Sand von Rio-San.Juan. No. 1. enthielt: orangegelbe zweigipflige Krystalle von Zirkon; Quarz in abgerundeten Körnern; Titaneisen in Formen des llmenits; Magneteisenerz; Arseneisen; Gold in Blättchen und abgerundeten Körnern.

No. 2. enthielt dieselben Mineralien wie No. 1., nur liein Arseneisen; statt dessen aber ein zweifellaftes Stückchen Cymophan.

Fine andere Sandprobe, mit No. 10. bezeichnet, enthielt: Titaneisen; Almandingranaten von verschiedener Grösse; Spessartingranaten (Mangangranaten), topasgelb, und kleine bratne Geschiebe, ähnlich denen, die in Brasilien Cabocle heissen und sich besonders im diamantfiihrenden Sande finden.

Sodann Sand, mit No. $36-876$. bezeichnet, enthielt: Eisenglanz, Titaneisen und Nickeleisen (Baierin).

Sand von Cinnago. No. 443. Bestand aus sehr feinen Körnern, und zwar aus 65 Proc. farblosen, zweigipfligen Zirkonkrystallen, 30 Proc. Titaneisen und 5 Proc. Magneteisen.

Das 'Titaneisen enthielt 48,14 Proc. Titansäure, 50,17 Procent Eisenoxydul und 1,69 Proc. Manganoxydul.

Sand von Taddo-Choco. Stammte von der Platinwäsche. Er enthielt: Titanhaltiges Magneteisenerz; Titaneisen in Form des Ilmenits; farblosen Zirkon; orangegelben Zirkon; Gold in Blaittchen und einzelne Quarzkörner.- (Dumour i. Descloizenax, Ann. de Chim. et de Phys. 3. Sér. Déc. 1857. Tom. LI. p. 445-450.) Dr. H. Ludwig.

\title{
Ueber den Smaragd
}

hat B. Lewy Beobachtungen und Analysen veröffentlicht.

Die mittlere Zusammensetzung des Smaragds aus der Mine von Maso in Neu-Granada ist nach Lewy:

\begin{tabular}{|c|c|c|c|}
\hline Kieselerde......... & 67,9 Proc. & $\begin{array}{c}\text { Sauerstoff } \\
35,4\end{array}$ & $\begin{array}{c}\text { Verhältniss } \\
4,2\end{array}$ \\
\hline T'honerde......... & $17,9 \quad$ & 8,3 & 1 \\
\hline Süsserde.......... & 12,4 & 7,8, & \\
\hline Talkerde ......... & 0,9 & $0.4 \quad 8,4$ & 1 \\
\hline 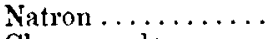 & 0,7 & $0,2 !$ & \\
\hline \begin{tabular}{l|l} 
Chromoxyd & Spuren \\
Titansïure & Sure
\end{tabular} & & & \\
\hline
\end{tabular}

Dies führt zur Formel $\mathrm{Al}^{2} \mathrm{O}^{3}, 2 \mathrm{SiO}^{3}+\mathrm{Gl}^{2} \mathrm{O}^{3}, \mathrm{SiO}^{3}$. Schon Scherer, Thompson und C. Gmelin gaben das 
Verhältniss $1: 1: 4$ an, während $D u$ frenoy in seinem Traité de Minéralogie dasselbe fälschlich $=1: 1: 5$ setzt.

Der Smaragd enthält eine gewisse Menge Wasser (1,66 Proc. im Mittel) und etwas organische Substanz (im Mittel nur 0,12 Proc.), wahrscheinlich einen Kohlenwasserstoff. Die unorganische, nicht-flüchtige Substanz beträgt im Mittel 98,22 Procent.

Da der Smaragd nur eine Spur Chromoxyd enthält (höchstens einige Zehntausendstel), so ist es unwahrscheinlich, dass er seine Farbe dem Chromgehalte verdankt. Lewy hält jenen organischen Kohlenwassersoff für das färbende Princip. Dafür spricht, dass der Smaragd nach dem Rothglühen farblos und undurchsichtig wird. Der Uwarowit (ein Chromgranat), welcher nach Damour 23,5 Procent Chromoxyd enthält, besitzt dieselbe grüne Farbe wie der Smaragd, verliert aber dieselbe durch Glühen nicht.

Nach Lewy ist die Bildung des Smaragds auf nassem Wege vor sich gegangen.

Der schwarze Kalkstein mit weissen Adern, in welchem die Smaragde von Muso, eingebettet liegen, enthält auch etwas Süsserde (etwa $5 / 10000$ ) in seiner Masse vertheilt. Lewy fand darin:

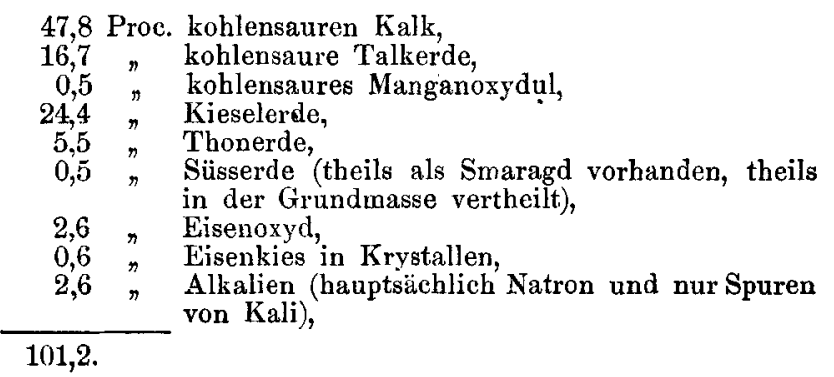

(Ann. de Chim. et de Phys. 3. Sér. Mai 1858. Tom. LIII. pag. 5-26.)

Dr. H. Ludwig.

\section{Hygroskopische Figenschaften der Zeolithe.}

Man verdankt $\mathrm{Ch}$. Sainte-Claire Deville die sinnreiche Bemerkung, dass jede Species der Zeolithe einen der Typen des Genus Feldspath entspricht, dass also Orthoklas, Albit, Oligoklas, Andesin, Labradorit und Anorthit jeder seine zugehörigen Zeolithe besitze, die mit ihnen dasselbe Verhältniss des Alkalis, der Thonerde und 